\section{THE REVERSAL OF HALL'S PHENOMENON}

$\mathrm{IN}$ a recent communication to the Physical Society I mentioned among other things that $I$ had succeeded in reversing the direction of the Hall effect in iron. It was, however, found to be so exceedingly difficult to keep the two points where the galvanometer connections were made at the same potential, even for a few seconds, that the extent of the deflections due to the Hall effect conld only be roughly guessed at, and the experiment was hardly a satisfactory one. I believe this inconvenience arose from the fact that the iron, being a strongly maunetic metal, was slightly displaced whenever the polarity of the electromagne was reversed, thus shifting the points of contact with the gal vanometer wires. I have since repeated the experiment with gold, which turns out to be perfectly easy to work with, and altogether more suitable for the purpose. The following is an account of four experiments :-

Experiment I.-A piece of nearly pure gold foil $5 \mathrm{~cm}$. lon and $3.5 \mathrm{~cm}$. broad was cemented to a plate of glass and the whole placed between the flat pole pieces of an electromagnet. 'The middle points, A, B (see figure) of the longer sides of the foil were connected to a galvanometer, $\mathrm{G}$, and the middle points, C, F, of the shorter sides to a battery. A current was passed through the metal from left to right, and the electromagnet

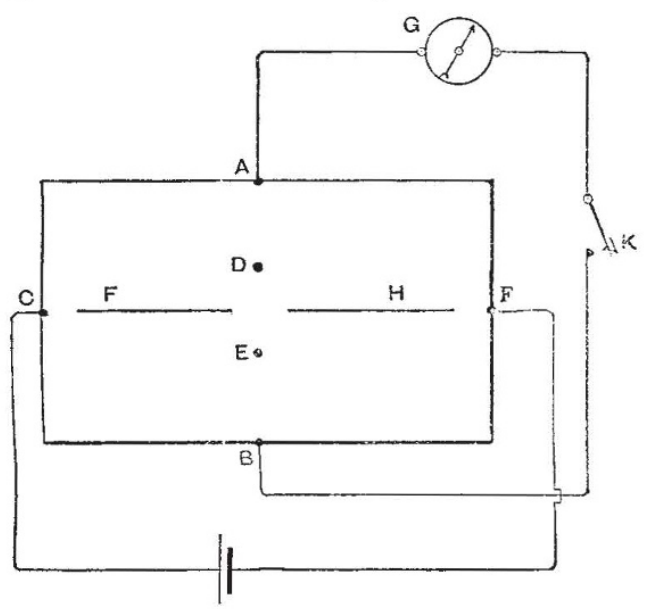

excited so that a south pole was beneath the glass and a north pole above it. The galvanometer was immediately deflected, indicating a current flowing in the direction B G A. If either the polarity of the magnet or the direction of the current through the foil was reversed, the transverse current was also reversed and flowed in the direction A G B. This is the ordinary "Hall effect," and the direction of the transverse currents agrees with that mentioned t,y Mr. Hall for gold. The extent of the deflections varied from about 50 to 70 scale divisions on each side of zero. Similar but smaller deflections occurred when the galvanometer was connected with points nearer to the middle of the plate.

Experiment 2.-Two longitudinal slits, $F, H$, about $\frac{1}{4} \mathrm{~mm}$. wide, were then cut along the middle of the foil, leaving a connection $4 \mathrm{~mm}$. wide between the two halves of the sheet, and the former experiment was repeated. The following are the details; and to under tand them it must be remembered that the galvanometer is affected by two causes besides the transverse current : (I) by the direct action of the electromagnet upon the galvanometer needle, though 13 feet away from it ; (2) by a small permanent current due to the fact that, however carefully adjusted, $\mathrm{A}$ and $\mathrm{B}$ are never (or hardly ever) at exactly the same potential.

The image of the galvanometer wire was brought as nearly as possible to zero of the scale before beginning the experiment, and the connections were made so that a current in the direction A G B caused a deflection to the left $(-)$, and a current in the direction B G A caused a deflection to the right $(+)$.

Upper pole of magnet north :-

\section{Galvanometer key, K, raised, deflection +25 divs. $^{1}$}

$$
\text { , ,, depressed, , + IO2 divs. }{ }^{2}
$$

1 Due solely to the action of the magnet upon the galvanometer needle.

2 Due partly to the action of the magnet on the galvanometer needle, partly to the permanent current above referred to, and partly to the transverse current resulting from magnetisation.
Upper pole of magnet south :-

Galvanometer key rai:ed, deflection - 24 divs.

$$
, \text {,, depressed, , }-42 \text { divs. }
$$

Net deflections due to current (subtracting effect of the magnet on the galvanometer needle) :Upper pole north $(102-25=)+77$ divs.
,,$\quad$ south $(-42+24=)-18$ divs.

Sum of opposite deflections due to transverse current, $(77+$ IS $=)$ 95, or deflection on each side of zero $=47 \cdot 5$ divs.

The slits therefore had the effect of reducing the amount of the Hall deflections; the direction was unaffected.

Experiment 3. - The galvanometer contacts were now moved from the edges to the point; $\mathrm{D}, \mathrm{E}$, about $5 \mathrm{~mm}$. from the middle line, and the experiment was repeated with the following result :-

Upper pole of magnet north :-

Key raised, deflection +18 divs.

, depressed, , +165 divs.

Upper pole south :-

Key raised, deflection - 35 divs.

," depressed, ,, + 180 divs.

Net deflections due to current :-

$\mathrm{U}_{1}$ per pole north $(165-\mathrm{I} 8=)+147$ divs.

, south $(180+35=)+215$ divs.

Sum of deflections $i$ ue to transverse current $\left(2 I_{5}-I_{47}=\right) 68$.

Deflection on each side of zero $=34$ divs.

Thus when the galvanometer contacts were near the middle of the plate the deflections were almost as great as when the galvanoweter was connected to the edges. But they zoere in the opposite direction, showing that the Hall effect was reversed.

Experiment 4.-A repetition of the last.

Upper pole $1.0 r t h:-$

$$
\text { Key raised, deflection }+28 \text { div: }
$$$$
\text { ,, depressed, ,, + I70 divs. }
$$

Upper pole south :-

Key raistd, deflection - 24 divs.

$$
\text { ", depressed, ,, + I } 70 \text { divs. }
$$

Net deflections due to current :-

$$
\text { Upper pole north }(170-28=) \text { I } 32 \text { divs. }
$$

$$
\text { ,, south }(170+24=) \text { I } 94 \text { divs. }
$$

Sum of deflections due to transverse current, $(194-132=) 62$

Deflection on each side of zero $=31$ divs.

These results, curious as they are, were of course not unexpected, the experiment baving becn in fact devised for the purpose of testing in an absolutely conclusive manner the sufticiency of the explanation of Hall's phenomenon by strains and Peltier effects which I have recently proposed (sce NATURE, p. 467 ).

Supposing the magnet and the battery to be so arranged that before the slits were made the points A and D were in stretched districts, and $B$ and $E$ in compressed districts of the metallic sheet, then the $\in$ ffect of cutting the slits will be practically to divide the plate into two independent pates, each of which undergoes strains similar to tho:e originally existing in the whole. $A$ and $B$ therefore will still be in regions which are respectively stretched and compressed, while on the other hand the region in which $\mathrm{D}$ is uill row be compressed, and that in which $\mathrm{E}$ is will be stretched. Thus as regards the points $D$ and $E$ the result of making the slits is to reverse the strain, and in consequence the PeItier effects and the galvanometer deflections. If Mr. IIall's own theory were correct, the existence of the slits shculd make no appreciable difference of any kind. That they should have the effect of reversing the action of the magnet upon the current is altogether inconceivable. SHELFORD BIDWELL

\section{DR. FEUSSNER'S NEW POLARISING PRISM}

$\mathrm{IN}$ a recent number of the Zeitschrift für Instrumentenkunde (iv. 42-50, February I884), Dr. K. Feu-sner of Karlsruhe has given a detailed description of a polarising prism lately devised by him, which presents several points of novelty, and for which certain advantages are claimed. The paper also contains an account, although not an exhaustive one, of the various polarising prisms which have from time to time been constructed by means of different combinations of Iceland spar. The literature of this subject is scattered and somewhat difficult of access, 